framum

Sociológico

\section{Forum Sociológico}

Série II

$24 \mid 2014$

Circulação de saberes e desafios em saúde

\title{
Lógicas de risco na experiência da sexualidade juvenil
}

Risk rationalities in the experience of youth sexuality

\section{Cristina Pereira Vieira}

\section{(Q) OpenEdition}

\section{Journals}

Edição electrónica

URL: https://journals.openedition.org/sociologico/1095

DOI: 10.4000/sociologico.1095

ISSN: 2182-7427

\section{Editora}

CICS.NOVA - Centro Interdisciplinar de Ciências Sociais da Universidade Nova de Lisboa

Edição impressa

Paginação: 89-94

ISSN: 0872-8380

\section{Refêrencia eletrónica}

Cristina Pereira Vieira, «Lógicas de risco na experiência da sexualidade juvenil», Forum Sociológico [Online], 24 | 2014, posto online no dia 01 novembro 2014, consultado o 31 março 2022. URL: http:// journals.openedition.org/sociologico/1095 ; DOI: https://doi.org/10.4000/sociologico.1095

Este documento foi criado de forma automática no dia 31 março 2022.

(c) CICS.NOVA 


\section{Lógicas de risco na experiência da sexualidade juvenil ${ }^{1}$}

Risk rationalities in the experience of youth sexuality

Cristina Pereira Vieira

\section{Introdução}

1 A constante mutação do mundo moderno dissolve o indivíduo num mundo líquido (Bauman, 2001; 2005), onde tudo nos invoca a escapar de nós próprios e a lidar com uma multiplicidade de possibilidades oferecidas por praticamente todos os aspetos da vida quotidiana. Um quotidiano em que os padrões de comunicação circulam num espaço e num tempo que deixaram de ser biunívocos. Num momento em que a modernidade fluida não se fixa e está constantemente disponível para a mudança. Associado a esta caraterística, o indivíduo move-se num contexto menos autoevidente, onde os poderes passaram de um nível "macro" para um nível "micro" do convívio social. Ou seja, passaram do sistema para a sociedade e da política para as Políticas da vida, onde o peso das normas associado à responsabilidade pelo sucesso ou insucesso se retratam no indivíduo (Bauman, 2005). No contexto da modernidade tardia é atribuída ao indivíduo, organizado reflexivamente, a responsabilidade pelo planeamento estratégico da sua vida (Giddens, 1997). Nesta perspetiva, o quotidiano, pensado de forma dinâmica e construído através de uma relação dialéctica entre a realidade subjetiva e as diferentes expectativas sociais, é permanentemente (re)construído. Subjacente a cada "escolha", emerge uma variedade de fatores, de rotinas quotidianas, de constrangimentos, de poderes, etc., que de alguma forma nos condicionam na tomada de decisões (Giddens, 2000).

2 Simultaneamente, a variedade de escolhas e de possibilidades do contexto póstradicional coloca o indivíduo numa cultura de oportunidades e riscos - riscos pessoais e riscos globais - contraditórios. Em ambiente de ambivalência, o indivíduo é obrigado a compreender e a gerir as diferentes oportunidades e riscos com base numa construção cognitiva e social (Beck, 2000). Ou seja, hoje a escolha tornou-se obrigatória 
e analiticamente podemos mesmo afirmar que todas as áreas da atividade social se tornaram governadas por decisões. No entanto, convém salientar que muitas destas nossas decisões estão subjacentes a uma pluralidade conflitual de saberes que plastificam as práticas sociais. 0 que percebemos hoje é que muitas das nossas escolhas não são universalmente estabelecidas com base nas pretensões do conhecimento pericial (Giddens, 2000), e isto também no caso concreto da sexualidade.

3 A crescente aplicação da ciência que na sua fase hegemónica, no século XIX, veio justificar procedimentos em matéria de saúde, higiene e estrutura da população assentou na universalização do conhecimento. Este novo exclusivismo epistemológico (Santos, 2004) com uma competência superior de conhecimento, no caso concreto, ajustado à medicalização da sexualidade, atribui uma natureza médica a práticas $\mathrm{e}$ problemas, que, até aí, não eram entendidos dessa forma. A medicalização da sexualidade passa a produção do saber suportada pela estimulação dos corpos, intensificação dos prazeres, desenvolvimento de conhecimentos e discursos e do reforço das fiscalizações e resistências. A partir desta explosão discursiva (Foucault, 1994), que na sua essência assentava na ideia de poder enquanto produtor de conhecimento, a sexualidade torna-se um campo de importância estratégica.

4 Assim, as novas produções do saber, na medicina e na psiquiatria, vêm construir um discurso de biologização da sexualidade, assente na dualidade normal/desviante (Weeks, 2003). Durante a década de 50/60 do século XX, com Alfred Kinsey (1948 e 1953) e mais tarde Masters e Johnson (1957 e 1965), as questões da sexualidade assumem uma visão mais centrada no bem-estar pessoal e com o parceiro, remetendo as questões da (a)normalidade da sexualidade para segundo plano. O trabalho de Kinsey, documentando uma diversidade de comportamentos sexuais, indicou que as formas "perversas" existiam numa perfeita continuidade da vida "normal". Do contexto sociocultural das décadas de 60 e de 70 resulta uma liberalização sexual, com significativas alterações na intimidade e na sexualidade individual e social. A partir do final da década de 60, o incremento da comercialização da pílula e de vários métodos contracetivos seguros (fenómeno que ficou conhecido como a segunda revolução contracetiva) veio contribuir de forma significativa para a emancipação da mulher e alteração do entendimento da sexualidade pelas mulheres e pelo casal, com um decrescente número de gravidezes indesejadas. "En France, il suffi de deux décennies pour que les méthodes médicales se substituent à peu près complètement aux méthodes traditionnelles" (Bozon, 2002: 31). Esta «idade do ouro», assim, designada por Bozon, sofre um revés com o surgimento da epidemia de infeção do HIV/sida, em meados dos anos 80. O desconhecimento da doença, provocada pelo VIH, por parte da ciência não permitia responder de forma convincente aos problemas da doença que era associada a "grupos de risco", grupos percebidos com comportamentos desviantes, incluindo uma sexualidade marginal - principalmente homossexuais, heroínodependentes e prostitutas. Numa fase inicial, a "epidemia das minorias" não dava, por isso, razões para alarme à população em geral (Daniel \& Parker, 1993). No entanto, o tempo deixou perceber que a infeção se propagava não em função dos grupos, mas dos designados "comportamentos de risco", passando, por isso, a ser objeto de programas específicos de prevenção médica, alargado a todos os indivíduos, e assente no discurso da proteção, através do uso do preservativo. Até hoje, as sucessivas orientações e legislações têm desenvolvido uma conceção de sexualidade associada à implementação de intervenções preventivas, através da promoção de competências pessoais e sociais, 
colocando a sexualidade como um assunto do domínio público, fundamentada por discursos reguladores.

5 Apesar do investimento nas campanhas e intervenções preventivas, nomeadamente contra a gravidez indesejada e contra as IST/sida, estas situações estão longe de desaparecerem (Beltzer, 2008). O que percebemos através de alguns estudos (Beltzer, 2008; Vieira, 2012) é que a lógica da saúde preventiva, quando não é colocada em segundo plano, entra frequentemente em concorrência com lógicas sociais que estruturam as práticas sexuais e preventivas. Nomeadamente, o que percebemos é que a noção de risco não é ignorada, mas constantemente nas práticas sexuais e preventivas ela é como que "esquecida" ou "relativizada", isto é, não convocada.

\section{Enquadramento metodológico}

6 A pesquisa decorreu no ano de 2008. Utilizou o método de grupos de discussão. Foram realizados seis grupos (27 raparigas e 27 rapazes) o que permitiu obter uma variabilidade discursiva. 0 critério de seleção da amostra combinou características homogéneas (idade entre os 17 e os 25 anos de idade e escolaridade ${ }^{2}$ em cada grupo) com heterogéneas (o sexo dos jovens participantes - rapazes ou raparigas). A combinação destas características permitiu, por um lado, manter uma simetria de relação entre os elementos do grupo e, por outro, assegurar a diferença necessária em todo o processo da discussão (Delgado \& Gutiérrez, 1994). As reuniões dos grupos foram videogravadas e transcritas na totalidade. A análise foi realizada com base em categorias construídas a partir dos discursos obtidos.

\section{Medos e riscos: uma dupla entrada na iniciação sexual/coital}

7 Quando se referem à experiência da primeira relação sexual coital, a quase totalidade dos jovens, dos vários grupos, evidencia a sensação de mal-estar, exposta através de expressões de "desilusão" e "insegurança"; da "forma desajeitada" e "desconfortável"; da manifestação de "dor" pelas raparigas; de desânimo (pela rapidez do ato) pelos rapazes e, nestes, ainda pelo medo de "não ser capaz".

Embora o sentimento de mal-estar seja generalizado, percebemos que este aparece ancorado na categoria de género. Ou seja, há diferenças na construção discursiva sobre as circunstâncias necessárias e sobre os medos associados à tomada de decisão. De uma maneira geral, os discursos dos rapazes atribuem a angústia da primeira relação sexual/coital a elementos de desempenho, quer quando manifestam o medo que tiveram de não serem capazes da execução (associado ao medo da grande brevidade do ato), quer através da ejaculação precoce. 0 medo dos rapazes está intimamente relacionado com a execução. É ao medo de falhar que se atribui o adiamento da concretização da primeira relação sexual.

G3M2:18 - [...] também há quem demore mais a decidir por causa dos medos, o medo de fazer, porque pode acontecer aquilo, não ser capaz de... e com esses medos demora mais a avançar... 
Estes discursos surgem associados a preconceitos sociais ancorados em lógicas profundamente genitalizadas e falocêntricas, especificamente inerentes à masculinidade viril.

Diferentemente, para as raparigas, a primeira relação sexual/coital aparece eminentemente ligada ao sentido de responsabilidade, no sentido em que relacionam a tomada de decisão de passar ao ato com o "estatuto" assumido de maturidade, num entendimento subjetivo.

G2F1:18 - [...] Se é aos 15, se é 16 ou aos 11, como se vê agora que os jovens perdem a virgindade, eu acho que isso é decisão de cada um ... eu acho que uma pessoa aos 12 pode ter a maturidade que uma pessoa só tem aos 16 . Acho que isso depende de pessoa para pessoa.

11 Para elas, as exigências não estão centradas no desempenho, mas nas consequências do ato, nomeadamente o risco de engravidar e o risco de serem abandonadas pelo parceiro.

G4F2:18 - Não há idade certa... cada um... quando se sentir preparada.

G4F3:20 - Foi o que eu disse, eu senti-me preparada. Mas foi aos 17 anos.

G4F4:19 - Mas depende... uma chavala de 13 anos...

G4F3:20 - Sim, mas já se sentem..., por exemplo de 13 anos, há miúdas que já se sentem preparadas.

G4F4:19 - Depois acontece de ficarem grávidas.

G3F2:19 - [...] porque se for a ver, uma pessoa engravida e quem fica com os filhos somos nós, os rapazes fogem ... [RISOS] [...].

G3M4:19 - E acho que as raparigas também têm um bocado mais de medo porque, é aquela coisa, tipo: - "ele faz comigo e se calhar deixa-me". Acho que com os rapazes não é tanto essas coisas, tipo fazem e... está tudo bem. E acho que com as raparigas não, elas ligam mais a essas coisas.

12 O que percebemos é que, apesar de uma das mudanças das últimas décadas estar associada a uma homogeneização das experiências entre rapazes e raparigas, no que respeita a iniciação sexual coital (Bozon, 2008), os significados atribuídos por eles e elas são diferentes. A permanência de significados e símbolos culturais que operam nos discursos e nas práticas, reproduzindo categorias de género, deixam entender que as raparigas vivem esta experiência como um compromisso afetivo e os rapazes como uma etapa da sua trajetória juvenil.

13 A primeira relação sexual/coital atua, através da representação de categorias de género, nos rapazes, profundamente associada à masculinidade viril e, nas raparigas, às consequências do ato, manifestado pelo medo de engravidar e pelo medo de não concretizar uma relação com propósitos conjugais.

\section{Duplo-padrão nos medos e riscos na lógica relacional}

Assentes em expectativas culturais distintas, rapazes e raparigas têm lógicas relacionais diferenciadas, quer na compreensão dos comportamentos, quer nos objetivos de concretização.

Assim, o que percebemos é que as raparigas projetam na sua trajetória biográfica um modelo de relação séria (assim designada) ou namoro, ou seja, uma relação que envolve cumplicidade e ultrapassa a simples atração física. A este significado estão associados sentimentos de intimidade sexual e de pertença que se projetam no tempo. 
G7F2:21 - Eu entendo por relação séria uma relação que dure algum tempo e que envolva sexualidade e não aqueles namoricos.

[...]

G7F3:23 - Eu identifico-me com ela... A Relação séria, ao nível da intimidade, é a partilha de determinadas coisas na vida que não partilhamos com qualquer pessoa a intimidade é vivida. Eu, pelo menos, tive duas relações sérias. [...].

Nos rapazes, a trajetória é traçada por dois momentos diferentes: um período de "experimentação/recriação" (designado por: comer, andar e curtir) e o período de relação séria (namoro).

G3M3:21 - O rapaz também pensa um pouco nisso, só que se calhar não é tanto.

G3M2:18 - O rapaz é... é como ele disse há bocado, agora é, como se diz, o curtir a vida, depois mais tarde depois vê-se.

G3M3:21 - Um rapaz é capaz de ir ter com uma rapariga e... depois de a ter, a seguir, vai tentar escolher outra rapariga, e depois outra e depois outra... enquanto que se calhar a rapariga já pensa o contrário: é aquele rapaz e é para casar naquele rapaz.

17 A partir de uma perspetiva diferenciada sobre a trajetória de experimentação da sexualidade, reencontramos o entendimento moral de que a socialização sexual das raparigas é mais controlada (impregnada de uma visão de sexualidade responsável, madura, preocupada e cautelosa) e surge remetida à responsabilização. Nos rapazes, a trajetória sexual passa por um período legitimado de experimentação/recreação, que lhes permite construir uma sexualidade a partir de diversificados relacionamentos e conquistas - o que, de certa forma, valida uma menor responsabilização social relacional.

18 Estas distintas vivências da sexualidade, assentes nas expectativas de género, produzem medos e riscos diferenciados. Apesar de afirmarem a preocupação com o risco de IST/ sida, os/as jovens demonstram desvalorizar a sua vulnerabilidade individual, nomeadamente na relação diária. Vários fatores apresentam-se ligados a esta atitude. 0 impacto das IST/sida nas suas vidas não é sentido de forma imediata - ao contrário da gravidez, que tem implicações no quotidiano imediato. Nas implicações efetivas do ficar grávida, há uma carga simbólica estigmatizante profundamente interiorizada.

G3M5:20 - Não sei, é aquele tal preconceito de chegar a casa, não é? E virar-me para a minha mãe ou para o meu pai: - "Ó mãe, ó pai, estou grávida. Vou ser mãe." [RISOS] ... do que, se calhar, se tiver uma doença, às tantas ninguém vai notar... talvez seja um bocado assim, não sei, não sou rapariga... mas é próprio dizer isso..

[...]

G3M3:21 - Por exemplo, se chegar à beira do meu pai: - "Vou ser pai!", é complicado. Se calhar dava apoio, mas eu falo por mim, tipo, [...] A nossa vida muda completamente.

G3F2:19 - Mesmo que tivesses uma doença, também ia mudar.

G3M3:21 - Mas se calhar a longo prazo. Enquanto se calhar uma gravidez era naquele momento...

19 Em termos globais, encontramos uma avaliação geral negativa sobre o uso do preservativo. A tónica é colocada na diminuição do prazer sexual, mas o significado aparece ligado à representação de liberdade. O preservativo é contranatura, referido como uma sensação "de pele com plástico" (G4M4:21). O uso do preservativo aparece também associado ao incómodo de obrigar a uma interrupção na relação sexual, o que parece ser embaraçoso. Paralelamente, e adotando o discurso da racionalidade médica, fazem referência à necessidade do uso do preservativo na primeira relação sexual/ coital e em todas as primeiras vezes de um novo relacionamento. Porém, fica claro que este não é um comportamento sempre efetuado, como se vê, por exemplo, no discurso 
de uma jovem quando refere que não usou preservativo porque já namoravam há muito tempo.

G7F3:23 - Não, quando perdi a virgindade não usei preservativo. Tomava a pílula. Já tomava porque inicialmente comecei a tomar a pílula, não por questões de engravidar, mas por questões hormonais... mas já foi ao fim de muito tempo de namoro, mesmo que [teve relações sexuais com penetração].

No sentido do não uso sistemático do preservativo em relações eventuais está também a informação de que não têm por hábito trazer o preservativo com eles/elas, dado que é costume esconderem-no em casa. $\mathrm{O}$ debate de um dos grupos foi claro quanto ao aspeto de que nem sempre sentem necessidade de usar qualquer método de contraceção. Circula a ideia de que, quando o casal se conhece bem e há intimidade, existe um controle da relação sexual - dando a entender o recurso ao coito interrompido. No entanto, para estes/as jovens, a partir do momento em que o relacionamento assume uma certa estabilidade, o preservativo é frequentemente substituído pela pílula. Esta prática vem confirmar o entendimento do uso do preservativo como prevenção de gravidez. Na generalidade dos discursos, prevalece a ideia de "imunidade da relação séria”, no sentido de não risco de IST, exteriorizado pela confiança mútua entre parceiros - situação confirmada pela investigação realizada com mulheres adultas de grupos sociais desfavorecidos (Vieira et al., 2003) e com homens adultos (Almeida e Vilar, 2008). Ou seja, o que percebemos é que no percurso da relação, o preservativo, como método de contraceção, tem um uso temporário, fixado mais numa fase inicial.

G5F3:18 - A pílula protege-te das doenças?

G5F4:21 - Claro que não, mas ele está a falar numa relação estável. Não é andar aí... quem anda à frente a torto e a direito usa preservativo.

G5M5:18 - Quando é uma namorada fixa, não é preciso preservativo.

21 Apesar de um dos grupos (jovens universitários) dar a entender que a preocupação com o risco se mantém numa "relação séria", manifestando estar em permanente alerta, facto que parece indicar que a "relação séria" não é sempre entendida como uma condição de imunidade, na prática, a argumentação resulta em desvalorização do risco de IST. Associado a este discurso está a relativização do risco específico no que constitui uma referência ao contexto da sociedade do risco em que os indivíduos vivem, com o reconhecimento da probabilidade de ameaças várias no quotidiano - uma sociedade que se põe em risco a si mesma (Beck, 2000).

Associada a esta argumentação está a manifestação do desejo de confiar no "outro", o que aponta para a lógica da relação pura (Giddens, 1996). Daí que seja na relação séria que o risco de IST é considerado menor e que nela se possa abdicar do preservativo. A opção dos/das jovens que experienciam uma relação séria recai na pílula, sendo preterido o uso do preservativo. Mesmo no caso da referência a opções conjuntas, pílula e preservativo, a justificação reside na procura de segurança do ponto de vista de prevenção da gravidez. Nos discursos destes jovens o uso do preservativo não é apresentado como tendo por motivo a prevenção de IST/sida, mas principalmente com a perceção do risco - assumido como um risco menor do que o da pílula: - "nunca confiar plenamente na pilula, há sempre um risco“ (G7F2:21).

\section{Em suma:}

Verificamos que as práticas de prevenção de riscos associados à sexualidade implicam uma pluralidade conflitual de saberes e de emoções. Entre forças intrínsecas à 
biomedicina - representadas pelo uso do preservativo e da pílula -, forças morais subjetivas - representadas pela confiança na fidelidade do/a parceiro/a - e imposições inerentes a preconceitos sociais - representados pelo medo da gravidez pré-conjugal, o campo é de ambiguidades. A escolha da contraceção aparece condicionada pela lógica relacional. A opção dos/das jovens que experienciam uma relação séria é feita no sentido da tomada da pílula. A opção pelo uso do preservativo surge associada aos relacionamentos que ainda não evoluíram para um sentimento relacional mais vinculativo e, por vezes, à primeira relação sexual.

Apesar de uma declarada preocupação com os riscos de engravidar e/ou ser contaminado pelo $\mathrm{VIH} /$ sida, os/as jovens desvalorizam a sua vulnerabilidade na relação continuada. $\mathrm{O}$ sentido de risco atribuído às IST/sida surge desvalorizado. Na prática, o cuidado, declarado principalmente pelas raparigas, passa pela seleção dos namorados com um significado de imunidade ao risco atribuído a uma relação séria, que expressa confiança mútua entre parceiros. Percebe-se o manifesto desejo de confiar no parceiro, assente em princípios da relação pura (Giddens, 1996), que alicerça a relação no grau de compromisso existente e na relação de confiança e estabilidade (a longo prazo), com base na comunicação do casal.

Assim, e no contexto da lógica da prevenção, há uma fronteira complexa e fluida entre os dois tipos de racionalidades: pericial e leiga. o que percebemos é que muitas das escolhas de prevenção destes jovens não são universalmente estabelecidas com base nas pretensões do conhecimento pericial. É claro que o entendimento da sexualidade está ancorado na lógica da medicalização (Illich, 1975) que remete para a noção médica de saúde e para a moral de comportamento responsável (Jodelet, 1999; Sontag, 1993). Mas é um entendimento que comporta contradição, nomeadamente no que respeita ao cumprimento das normas pelas quais o saudável se avalia. Na prática, o conhecimento do saudável, que é adotado como crença, não se transforma necessariamente em disposição para agir (Lahire, 2005) - o que os estudos de sociologia "do saudável" encontram para a generalidade dos "comportamentos saudáveis" (Silva, 2008).

Se nos focarmos na complexidade subjacente à lógica da contraceção e às opções que dela emergem, verificamos que há uma variedade de fatores associados que ultrapassam o conhecimento pericial. Neste caso concreto, os/as jovens vão atenuando fronteiras rígidas entre o conhecimento não técnico e o pericial.

Em conclusão pode-se afirmar que as campanhas de prevenção de uma maneira geral, e em particular quando dirigidas aos jovens, não devem atender unicamente a um saber pericial, técnico ou especializado que informa o indivíduo, sem ter presente o conhecimento leigo. Estas devem estar atentas às designadas tecnologias populares ${ }^{4}$, dando voz ao conhecimento leigo. Ou seja, sem eliminar as fronteiras entre conhecimento leigo e pericial, há que perceber, nesta distinção complexa, fronteiras plásticas que vão possibilitando aos indivíduos um conhecimento das questões técnicocientíficas e aos técnicos um conhecimento da importância das forças morais e subjetivas, representadas pela confiança na fidelidade do/a parceiro/a; dos preconceitos sociais, representados pelo medo da gravidez pré-conjugal e da lógica da escolha da contraceção, condicionada pelo modelo relacional de relação séria ou por modelos de relacionamentos esporádicos. Será porventura neste aprofundamento do interconhecimento que a avaliação dos riscos, no caso concreto da sexualidade, e dos medos provocados pelas incertezas envolvidas, terão por base uma construção de critérios técnicos mais amplos e seguros (Santos, 2004). 


\section{BIBLIOGRAFIA}

ALMEIDA, A. e D. Vilar (2008), "Literacia e práticas contraceptivas masculinas", Sexualidade e planeamento familiar, n.ำ50/51; Julho/Dezembro, Lisboa, pp. 34-42.

BAUMAN, Z. (2005), Identidade, Rio de Janeiro, Jorge ZAHAR Editor.

BAUMAN, Z. (2001), Modernidade Líquida, Rio de Janeiro, Jorge Zahar Editor.

BECK, U. (2000), “A reinvenção da política”, in U. Beck, A. Giddens, A. e S. Lash (eds.), Modernização reflexiva, Oeiras, Celta Editora.

BELTZER, N. e N. Bajos (2008), "De la contraception à la prévention: les enjeux de la négociation aux différentes étapes des trajectoires affectives et sexuelles”, in N. Bajos e M. Bozon (eds.), Enquête sur la sexualité en France: pratiques, genre et santé, Paris, La Découverte, pp. 437-460.

BOZON, M. (2002), Sociologie de la sexualité, Paris, Nathan Université.

BOZON, M. (2008) “Premier rapport sexuel, première relation: des passages attendus”, in N. Bajos e M. Bozon (eds.), Enquête sur la sexualité en France: pratiques, genre et santé, Paris, La Découverte, pp. 117-147.

DANIEL, H. e R. Parker (1993), Sexuality, politics and AIDS in Brazil, London, The Falmer Press.

DELGADO, J. e J. Gutiérrez (1994), Métodos y técnicas cualitativas de investigación en ciencias sociales, Madrid, Editorial Síntesis.

FOUCAULT, M. (1994), História da sexualidade I - A vontade de saber, Lisboa, Relógio D’Água.

GIDDENS, A. (1997), Modernidade e Identidade Pessoal, Oeiras, Celta Editora.

GIDDENS, A. (1996), Transformações da intimidade: sexualidade, amor e erotismo nas sociedades modernas (2. ${ }^{a}$ Ed.), Oeiras, Celta Editora.

GIDDENS, A., V. Beck e S. Lash (2000), Modernização reflexiva, Oeiras, Celta Editora.

ILLICH, I. (1975), Némésis Médicale - L'expropriation de la santé, Paris, Seuil.

JODELET, D. ([1989] 1999), Les représentations sociales, Paris, Presses Universitaires de France.

KINSEY, A. (1948), Le comportement sexuel de l'homme, Paris, Éditions le Pavois.

LAHIRE, B. (2005), L'esprit sociologique, Paris, La Découverte.

MASTERS, W. e V. Johnson, et al. (1987), La sexualidad humana, Barcelona, Grijalbo.

SANTOS, B. (2004), Reinventar a Emancipação Social: Para novos manifestos - Semear outras Soluções, Porto, Edições Afrontamento.

SILVA, L. (2008), Saber Prático de Saúde: as lógicas do saudável no quotidiano, Porto, Edições Afrontamento.

SONTAG, S. (1993), La maladie comme métaphore/Le Sida et ses Métaphores, Paris, Christian Bourgeois Éditeur.

VIEIRA, C. (2012), Eu faço sexo amoroso - A sexualidade dos jovens pela voz dos próprios, Lisboa, Editorial Bizâncio.

VIEIRA, C., L. Silva et al. (2003), Comportamentos de risco em mulheres portuguesas, http:// www.aidscongress.net/4congresso.php. 
WEEKS, J. (2003), Sexuality, London and New York, Routledge, $2^{\text {nd }}$ ed.

\section{NOTAS}

1. Comunicação apresentada no V Congresso Ibero-Americano de Pesquisa Qualitativa em Saúde - Circulação de Saberes e Desafios em Saúde, realizado em Lisboa entre 11 e 13 de Outubro de 2012.

2. 3 grupos com jovens cujo nível de escolaridade não é superior ao 3.․․ ciclo (frequentavam os cursos profissionais do Ministério da Educação ou do Ministério do Trabalho e da Solidariedade Social) e 3 grupos com jovens pré-universitários, universitários ou licenciados.

3. G3M2:18 = G3 (Grupo n.o); M2 (Masculino, jovem colocado na posição 2 no grupo); 18 (Idade do jovem).

4. Termo que Boaventura Sousa Santos defende como conhecimentos que podem ter origem num saber considerado não técnico pela ciência moderna.

\section{RESUMOS}

O domínio da contraceção é um campo de ambiguidades entre as forças modernas de racionalização (representadas pelo uso do preservativo aconselhado pela medicina para prevenir o risco de IST/sida), as forças morais subjetivas (representadas pela confiança na fidelidade do/a parceiro/a) e os preconceitos sociais (representados pelo medo da gravidez pré-conjugal). Claramente, a opção de contraceção funciona no modelo relacional. $\mathrm{O}$ artigo apresenta dados de estudo empírico com jovens portugueses(as), pela técnica de grupos de discussão. A análise dos dados mostra como nas racionalidades leigas a avaliação dos riscos na sexualidade (aqui referidos relativamente à IST/sida e à gravidez), a lógica da contraceção e as opções que dela emergem aparecem incrustadas a valores, símbolos e significados que ultrapassam a lógica da racionalidade científica e que justificam uma não total adesão à normatividade. $O$ que nos leva pensar que as campanhas de promoção da saúde sexual e reprodutiva, em particular quando dirigidas aos jovens, não devem atender unicamente a um saber pericial, técnico ou especializado que informa o indivíduo, sem ter presente o conhecimento leigo.

Contraception is a domain of ambiguity between forces of modern rationalization (represented by condoms to prevent the risk of IST/AIDS), subjective moral forces (represented by confidence in partner's fidelity) and social prejudices (represented by fear of premarital pregnancy). The choice of contraception operates in the relational model. This paper presents data from an empirical research with Portuguese youngsters via focus groups. Data analysis shows how lay rationalities of risk assessment in sexuality (namely regarding STI/AIDS and pregnancy), the logic of contraception and the options involved appear embedded with values, symbols and meanings that go beyond scientific rationality and explain non-compliance to normativity. This suggests that promotion of sexual and reproductive health, particularly when targeting young people, should not only take in account technical expertise. 
ÍNDICE

Keywords: sexuality, youth, risk, relationships

Palavras-chave: sexualidade, jovens, risco, relacionamentos

\author{
AUTOR \\ CRISTINA PEREIRA VIEIRA \\ Docente na Universidade Aberta (UAb), Departamento Ciências Sociais e Gestão (DCSG); \\ Investigadora no Centro de Estudo das Migrações e Relações Interculturais (CEMRI) \\ (cristina.vieira@uab.pt)
}

